\title{
A SURVEY FOR THE PRESENCE OF THE AMPHIBIAN CHYTRID FUNGUS (BATRACHOCHYTRIUM DENDROBATIDIS) IN TASMANIA
}

\author{
by David Obendorf and Alexander Dalton
}

(with one plate, one text-figure and one table)

\begin{abstract}
Obendorf, D. \& Dalton, A. 2006 (30:xi) A survey for the presence of the amphibian chytrid fungus (Batrachochytrium dendrobatidis) in Tasmania. Papers and Proceedings of the Royal Society of Tasmania 140: 25-29. https://doi.org/10.26749/rstpp.140.25 ISSN 0080-4703. 7 Bonnington Road, West Hobart, Tasmania 7000, Australia (DLO*, AD). *Author for correspondence.

A survey confirmed the presence of the amphibian chytrid fungus, Batrachochytrium dendrobatidis in a number of frog habitats close to major cities and towns across Tasmania. The detection of chytrid infection in some remote wetlands at high altitude locations on the Tasmanian Central Plateau is of particular concern. The likely presence of chytrid infections was assessed by examining tadpoles for signs of depigmentation, thinning and asymmetry in their keratinized jaw sheaths using a hand lens. Assessing the jaw sheaths of up to 60 tadpoles combined with the application of the Taqman chytrid PCR test was a useful means of detecting the presence of chytridiomycosis at each frog habitat.
\end{abstract}

Key Words: chytrid, Batrachochytrium dendrobatiditis, frogs, disease survey, Tasmania.

\section{INTRODUCTION}

Batrachochytrium dendrobatidis is the only chytridiomycete fungus known to affect a vertebrate. This fungus completes its life cycle in the skin of amphibians, utilising keratin as a protein substrate (Powell 1993, Berger et al. 1998). Over the course of the past 40 or 50 years this organism has managed to enter, establish and spread on to every continent (except Asia) where amphibians exist (Daszak et al.1999, 2003, Stewart et al. 2004, Weldon et al. 2004). Insidiously the disease - chytridiomycosis - has become the agent of a global pandemic in amphibian populations. Several frog species are now believed to be extinct including six species in Australia (Anon 2005) as a direct result of the entry and establishment of this fungus into local ecologies (Lawrence 1996, Daszak et al. 2003).

The movement of frogs with trade produce, particularly bananas, is well recognised (McDonald \& Speare 2000, O'Dwyer et al. 2000). It has been hypothesized that the eventual escape or release of these frogs into local wetlands may be a probable means for the establishment of this pathogen in local populations of frogs (Hardman 2001, Obendorf 2005). The amphibian chytrid infection is now recognised as one of the major threatening processes causing the decline of frogs and salamanders across the planet (Anon 2006) and chytrid fungus, $B$. dendrobatidis is now listed as a key threatening process under the Commonwealth Environment Protection and Biodiversity Conservation Act 1999.

Tasmania was one region in Australia that had not reported chytrid $(B d)$ infection in its local frog populations, although there has been evidence of declines in the range and abundance of some species of frog in Tasmania that are susceptible to this infection (Anon 2006). Therefore the Central North Field Naturalists Inc. wished to investigate the cause of frog declines in Tasmania with particular focus on developing a practical field survey method and trialling a new DNA gene probe test for the presence of $B d$ in tadpoles at various frog habitats.

This paper describes the field and diagnostic methods applied to the detection of this cryptic pathogen in a part of Australia where the disease was suspected to occur but had not previously been recognised. An important aim of the Tasmanian $B d$ survey was to trial the effectiveness of these methods so as to support other community groups across Australia in conducting baseline and follow-up monitoring surveys for $B d$ infection in frog populations.

\section{MATERIALS AND METHODS}

During the spring and summer of 2005-06 the amphibian research group of the Central North Field Naturalists Inc. (CNFN) conducted a survey of frog habitats for the presence of chytridiomycosis. The survey relied on the use of a visual assessment of keratinized mouthparts of tadpoles, as a preliminary field assessment tool (Fellers et al. 2001) and the use of a highly sensitive and specific gene probe test (Boyle et al. 2004) to detect $B d$ in samples collected from tadpoles. Details of the full survey methods and the techniques used in the Tasmanian survey are outlined in Obendorf (2005).

\section{Field Surveys}

Prior to commencing the study, a $B d$ risk assessment was prepared for Tasmania and its frog fauna. This assessment covered issues such as the number of frog species at a survey site, potential susceptibility of the species present to $B d$ infection and the location of the frog habitat. All field surveys were conducted in accordance with a hygiene protocol for the control of disease in frogs (Anon 2001a, Speare et al. 2005).

Equipment (dip-nets, buckets, waders, gumboots and incontact survey equipment) was appropriately sterilised using effective biocides after each survey. Only one survey was undertaken per day so that all equipment could be adequately decontaminated and dried before re-use. At particular frog habitats where there were frog species deemed to have high susceptibility to $B d$, additional hygiene precautions were 
taken (e.g., the use of new dip-nets). These sites included locations remote from human habitation or human activities such as fishing, vehicle access or walking tracks.

Up to 60 tadpoles per site $($ mean $=35$, range $13-60$; no. of sites $=56$ ) were examined in the field surveys. $B d$-infected tadpoles can be provisionally identified by looking at their pigmented jaw sheaths and tooth rows using a hand lens (x10-12 magnification); bright natural illumination is necessary. Chytridiomycosis-induced mouthpart depigmentation was categorised as obvious areas of white beginning at the base of the normally black jaw sheaths causing the sheaths to appear thinner than normal or to show segmental loss of black pigmentation through a section of the sheath.

Each tadpole was assessed according to the following grading: 0 - normal jaw sheaths; 1 - thinning or asymmetry in any jaw sheath; 2 - obvious segmental depigmentation in any jaw sheath; 3 - substantial depigmentation or complete depigmentation in any jaw sheath. For the purposes of assessing the diagnostic effectiveness of this field survey method, the gradings from both the anterior (AJS) and posterior jaw sheath (PSJ) from each tadpole were recorded at each survey site (pl. 1.). The developmental stage of assessed tadpoles was required to be between Gosner stages 26 and 39 (Gosner 1960, Anstis 2002) because at stages less than 26, tadpoles are too small for manual handling and at stages greater than 39 tadpole mouthparts undergo changes as a result of metamorphosis. To minimise the chances that any observed jaw sheath depigmentation was not caused by cold water or freezing temperatures (Rachowicz 2002), cold climate sites were surveyed during the summer months.

A putative determination of $B d$ status was made if at least one tadpole with a total grading score of 2 or above was recorded at a survey site. Although $B d$ infection leads to depigmentation and changes to the teeth in the tooth rows, these changes were not included in the assessment as physical damage or loss of these delicate structures can be incorrectly ascribed to $B d$ infection whereas the extreme jaw sheath changes (gradings 2 and 3 ) when present are more likely to be attributable to $B d$ infection. Field assessors identified the tadpoles to species; graded each jaw sheath and assessed the Gosner development stage of each tadpole; these findings were recorded on field sheets by another surveyor. For details on the identification of Tasmanian frog species at the tadpole stage and Gosner development stages, see Anstis (2002) and Littlejohn (2003).

Inspection of jaw sheaths of tadpoles involves gently placing a tadpole on a moistened hand with the tadpole's head pointing toward the fingertips. By arranging the fingers such that the index and third finger slightly overlap the second finger, a tadpole can be carefully held and where necessary a small amount of pressure applied to the ventral body will encourage the jaw sheath to part for full examination. The hand lens under ambient light condition is sufficient to examine the tadpoles and grade the jaw sheaths. Considerable care must be taken in handling tadpoles and assessment should be done as quickly as possible so that tadpoles are out of water for the minimum time.

\section{Laboratory Diagnostic Tests}

The highly sensitive PCR amplification gene-probe was used as the definitive diagnostic test to diagnose chytridiomycosis - the Taqman PCR Bd assay (Boyle et al. 2004). During our field surveys we assessed a range of sampling techniques initially involving the sacrifice of up to six tadpoles per site for testing (Obendorf 2005). Selected tadpoles were killed using an overdose of the anaesthetic benzocaine. Using sterile technique to minimise any DNA contamination between samples, the oral disc of each sampled tadpole was excised and separately placed onto a filter paper. Filter papers were dried and labelled and separately stored in small zip-lock bags (Obendorf 2005). The filter paper samples were then tested using the Taqman PCR $B d$ assay.

In the latter stages of the survey, the CNFN amphibian survey group validated the use of a non-lethal sampling technique involving gently touching a fine tip swab onto the oral discs of tadpoles (MW100 fine tip swab - Medical Wire Equipment UK). 'This process, if applied with care, results in no permanent damage to tadpoles allowing all animals to be returned to their habitat (A. Dalton, unpublished data). The swabs were then dried in a low temperature desiccator to minimise DNA degradation prior to batch submission to the testing laboratory.

Care was taken not to cross-contaminate samples as only a small amount of contamination can lead to false positive results. The comparative effectiveness of the live swabbing

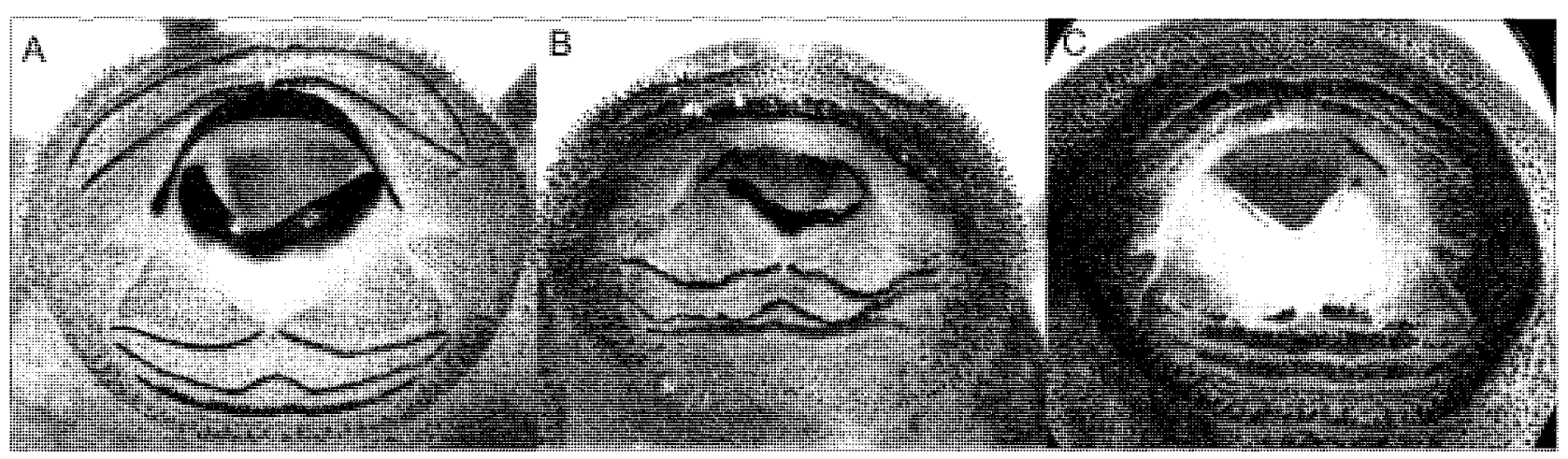

PLATE 1

Oral discs of Brown Tree Frog (Litoria ewingii) tadpoles with grading scores (AJS - anterior jaw sheath, PJS - posterior jaw sheath). (A) Normal mouthparts; total score $=0$. (B) Thinning and segmentation with almost complete loss of AJS (3) and thinning and asymmetry in PJS (1); total score $=4$. (C) Almost complete loss of both jaw sheaths AJS (3), PJS (3) with segmental loss of tooth rows; total score $=6$. 
method versus the necropsy oral disc sampling method will be reported elsewhere.

The CSIRO Australian Animal Health Laboratory in Geelong undertook the real-time Taqman PCR on the samples for the presence of amphibian $B d$ (Boyle et al. 2004).

The findings from the tadpole mouth part gradings at each survey site were compared to the results obtained from the laboratory PCR tests taken from the selected sub-sample of tadpoles from the same survey site.

\section{RESULTS}

\section{Survey Findings}

Batrachochytrium dendrobatidis was confirmed to be present in 33 of 56 Tasmanian survey sites. We compared the visual assessment method based on the presence of one or more tadpoles showing jaw sheath changes $\geq$ grading 2 and the results of the Taqman PCR test results from tadpoles sampled from the same site (table 1).

At 25 of 26 sites where one or more tadpoles had jaw sheath changes $\geq 2$, the site was confirmed to be $B d$ positive by the PCR gene probe. At one of 26 sites (4\%) where one or more tadpoles had jaw sheath changes $\geq 2$, the $B d$ PCR gene probe was negative. At 22 of 30 sites $(73 \%)$ where no tadpoles showed any visual jaw sheath abnormalities. a sub-sample of up to six tadpoles returned $B d$ negative results by the PCR gene probe. At eight of 30 sites (27\%) where no abnormal tadpoles were detected, a sub-sample of up to six tadpoles was $B d$ PCR gene probe positive. The status of the Walls of Jerusalem site is designated "probable chytrid positive" because only a small number of Criniaspp. tadpoles (13) was examined and the testing laboratory deemed the zoospore DNA replication to be low; they classified the PCR test result "indeterminate".

The conclusions drawn from this survey method are that where a moderate to high number of tadpoles show typical grade 2 to 6 jaw sheath abnormalities ( $>30 \%$ of all tadpoles), there is a very strong likelihood that the surveyed frog habitat is $B d$-infectious.

Using the $B d$ PCR gene probe as the definitive test for $B d$ presence at a frog habitat, a field survey of up to 60 tadpoles between Gosner stages 26 to 39 was successful at $84 \%$ of the sites surveyed. At only one survey site did the PCR probe not confirm the presence of $B d$ whereas the field survey suggested a putative positive result.

Using the $B d$ PCR test result as the definitive test for $B d$ presence or absence, the number of survey sites designated as $B d$-positive increased from 25 to $33(n=56)$.

Relying only on the field survey assessments is not recommended. If the visual assessment of the jaw sheaths in tadpoles is used as the only confirmatory test for the presence of $B d$ infection, it has the potential to occasionally give a false positive result ( $4 \%$ or 1 of 26 surveys) or a false negative result ( $27 \%$ or eight of 30 surveys). Natural or traumatic loss of a single jaw sheath, in the absence of any other abnormalities in the remaining jaw sheath and tooth rows, could be graded incorrectly. In addition, surveying tadpoles in advanced Gosner stages can also increase the likelihood of classifying the physiological loss of a jaw sheath incorrectly as a grade 3 change. An absence of jaw sheath changes in any tadpoles at a survey site has the potential to more frequently suggest that $B d$ infection is not present.
TABLE 1

Visual survey results compared to chytrid PCR results from 56 Tasmanian frog habitats

\begin{tabular}{lccc}
\hline $\begin{array}{l}\text { Chytrid } \\
\text { PCR Results }\end{array}$ & $\begin{array}{c}\text { Jaw sheath } \\
\text { lesions }\end{array}$ & $\begin{array}{c}\text { No jaw sheath } \\
\text { lesions }\end{array}$ & Total \\
\hline Positive & 25 & 8 & 33 \\
Negative & 1 & 22 & 23 \\
Total & 26 & 30 & 56 \\
\hline
\end{tabular}

Therefore where no jaw sheath abnormalities are found in any tadpoles at a given wetland, $B d$ PCR testing is always recommended.

\section{CONCLUSIONS}

Using the two methods (visual assessments of tadpoles and back-up PCR testing) the survey method showed that chytridiomycosis already has gained a wide distribution in Tasmania including several locations around the major cites of Hobart, Burnie, Devonport and Launceston as well as small towns and farming sites such as Dover, Seven Mile Beach, Hawley near Port Sorell and Elizabeth Town. The confirmation of $B d$ at remote sites such as Mother Cummings Plateau and Cradle Mountain National Park, in Tasmania's highlands suggests that the disease has also entered and established itself in remote and high altitude areas of Tasmania (fig. 1). Notably four locations with high frog biodiversity $(\geq$ six species) and with stronghold populations of Green \& Gold Frogs were shown to be currently free of $B d$ infection (e.g., Waterhouse Protected Area and Northdown).

The survey results identified at least six species of Tasmanian frog as having $B d$ infections in their tadpole stages. These are the Brown Tree Frog (Litoria ewingii Duméril \& Bibron, 1841), Green \& Gold Frog (Litoria raniformis Keferstein, 1867), Southern Banjo Frog (Limnodynastes dumerilii insularis Parker, 1940), Spotted Marsh Frog (Limnodynastes tasmaniensis Günther, 1858), Common Froglet (Crinia signifiera Girard, 1853) and Tasmanian Froglet (Crinia tasmaniensis Günther, 1864). Crinia spp. tadpoles were particularly difficult to assess visually because of their small body size and the somewhat concealed nature of their jaw sheaths.

\section{DISCUSSION}

Visual assessment of the jaw sheaths of tadpoles is a useful method of surveying frog habitats for the presence of $B d$ infection provided that surveyors are trained in distinguishing $B d$-induced changes in the jaw sheaths from natural damage or physiological changes with aging (Anstis 2002). The principal benefit of adopting this survey method for detecting $B d$ infection was the relative ease in catching tadpoles compared to adult and metamorphling frogs. Although aspects of the epizootiology of chytridiomycosis in frog populations are still unclear, we believe this methodology can be used to quickly assess the presence or absence of $B d$ infection. This is particularly relevant in wetlands or bioregions experiencing declines in the abundance and diversity of frog species and 


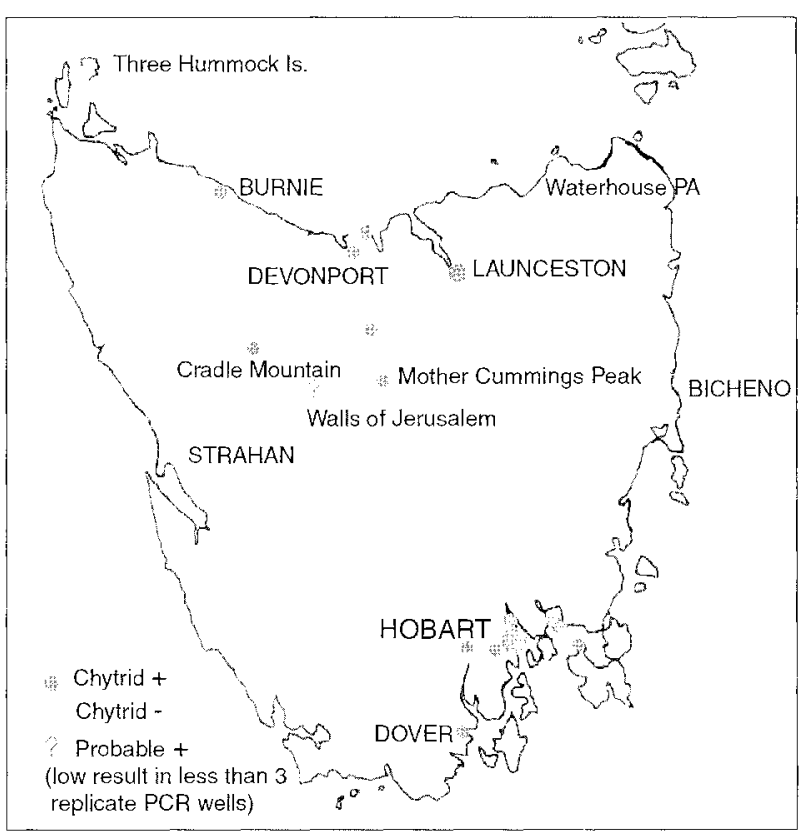

FIG. 1 - Tasmanian chytrid survey sites. Large dots designate $\geq 3$ survey sites within $10 \mathrm{~km}$ radius - Hobart 18 , Launceston 6, Cradle Mountain 4, Waterhouse 3, Three Hummock Island 3.

where other threatening processes have been discounted. As a preliminary test, the field survey is more accurate in determining the presence of $B d$ infection. The PCR gene probe test is, however, the definitive test for confirmation. At sites where there is evidence of frog declines or actual mortalities, samples from tadpoles or frogs for $B d$-PCR testing are recommended.

The use of fine-tipped swabs as the method for collecting laboratory samples has now superseded the need to extract the keratinized mouth parts from euthanased tadpoles. Swabbing allows the mouth parts of live tadpoles to be undertaken at the site of the field surveys without loss of life. Use of swabs also considerably reduces the potential problems of DNA cross-contamination. Field surveys of tadpoles can be undertaken from early spring to late autumn.

$B d$ infection was detected in a number of frog habitats close to the major cities and towns across Tasmania. Stronghold establishment of introduced species in the vicinity of human habitation is consistent with the hypothesis that mainland species of frogs entering with imported fresh produce (especially bananas and horticultural produce such as potted plants) are the most likely source for the establishment of chytridiomycosis in Tasmania (Hardman 2001, Obendorf 2005). Although water containing zoospores of $B$. dendrobatidis and other aquatic material carrying zoosporangia will survive for three to four weeks (Johnson \& Speare 2003), the ability of this fungus to successfully survive and spread in the environment in the absence of an amphibian host is unclear. Once $B d$ has entered and established in a new location - in this case Tasmania - subsequent spread may occur by a variety of natural and anthropogenic means.

We believe that the amphibian $B d$ fungus has been in Tasmania for more than two decades. A multiple frog mortality incident in Tasmania in 1993 was recently confirmed to be due to chytridiomycosis (Obendorf 2005). Across its Australian range, the Green \& Gold Frog (Litoria raniformis) has experienced dramatic declines especially in its inland habitats. This species is also recognised as being particularly susceptible to $B d$ infection (Anon 2006). In Tasmania L. raniformis was considered a common and populous species of frog until the early 1980s (Martin \& Littlejohn 1982); however, the species is now listed as vulnerable under the Tasmanian and Commonwealth threatened species legislation. The establishment of chytridiomycosis close to the main Tasmanian cities coincides with the locations where declines in $L$. raniformis abundance were initially reported. It has been argued that the decline in the range and abundance of $L$. raniformis is consistent with the introduction of this exotic pathogen (Obendorf 2005). Some coastal wetlands still retain large populations of $L$. raniformis and there may be specific environmental factors (e.g., salt concentration) at these sites that are unfavourable for the establishment of $B$. dendrobatidis (Anon 2006).

The confirmation of $B d$ infection in Crinia spp. tadpoles at remote wetlands on the Central Plateau is of concern. Over the past two decades several species of frog inhabiting high altitude montane regions in southeast Australia have experienced declines in abundance and range and are now the subject of threatened species recovery plans (Antis 2002, Gillespie \& Marantelli 2000, Berger et al. 2004). Such habitats incorporate the area of occupancy of all three Tasmanian endemic species: Tamanian Froglet (Crinia tasmaniensis), Tasmanian Tree Frog (Litoria burrowsae Scott, 1942) and Moss Froglet (Crinia (Bryobatrachus) nimbus Rounsevell, Ziegeler, Brown, Davies \& Littlejohn, 1994). The contraction in the range of the endemic L. burrowsae was first recognised by the Central North Field Naturalists in the 1990s (Jim Nelson, pers. comm.); the species was last recorded from its type locality (Cradle Valley) in 1997 (Alex Dudley, pers. comm.).

There is an urgent effort to assess the current distribution and potential impact of this disease on Tasmania's 11 native frog species. The Threat Abatement Plan for Infection of Amphibians with Chytrid Fungus Resulting in Chytridiomycosis (2006) notes that frogs from colder, high altitude habitats are particularly susceptible to $B d$ infection. Reported dramatic declines in the abundance and range of Litoria raniformis - a State and Commonwealth-listed threatened species - is also of particular concern as chytridiomycosis may be a key threatening process responsible in its decline in Tasmania (Anon 2001b). The ongoing movement of frogs and tadpoles where $B d$ infection is now endemic, in our view, is the greatest risk to the entry, establishment and spread of this significant fungal disease into new amphibian ecologies.

\section{ACKNOWLEDGEMENTS}

The authors wish to thank the volunteer surveyors Wade and Lisa Clarkson, Steve Cronin, Bill Flowers, Paul Swiatkowski, Jim Nelson, Debbie Hill and Ron Nagorka; Central North Field Naturalist treasurer, Sarah Lloyd for administering the DEH fund; CSIRO AAHL staff Donna Boyle and Alex Hyatt for Bd-PCR testing; the School of Zoology, University of Tasmania for local laboratory support, photographic expertise, field assistance, computer wizardry and fellowship; Dr Andrew Parker, Royal Hobart Hospital, Department of Health \& Community Services for photomicrography, Robert Walch, Walch Optics for ongoing support relating to microscopes and field cameras; Martin Harris and Karyl 
Michaels, WWF Frogs! Program Coordinator for practical support; Professor Rick Speare, James Cook University and Pearl Symonds of the Gap Creek, SE Queensland frog survey group for ongoing advice and support; Dr Rupert Woods, Australian Wildlife Heath Network for additional funding for $B d$ testing. Research conducted under permit number TFA 04193 issued by the Tasmanian Department of Primary Industries, Water \& Environment. Central North Field Naturalists Inc. received funding from the Natural Heritage Trust - Invasive Species Program.

\section{REFERENCES}

Anon. 2001a: Hygiene protocol for the control of disease in frogs. Threatened Species Management Information Circular No. 6 NSW National Parks and Wildlife Service: 17 pp.

Anon. 2001b: Threatened Species Listing Statement - Green and Golden Frog, Litoria raniformis Keferstein 1867. Tasmanian DPIWE Threatened Species Unit; March 2001.

Anon. 2005: Epidemic in Natural Heritage 26: 5.

Anon. 2006: Infection of amphibians with chytrid fungus resulting chytridiomycosis. Threat Abatement Plan: Background Document Australian Government Department of the Environment and Heritage.

Anstis, M. 2002: Tadpoles of South-eastern Australia. Reed New Holland, Australia: $281 \mathrm{pp}$.

Berger L., Speare, R., Daszak, P., Green, D.E., Cunningham, A.A., Goggin, C.L., Slocombe, R., Ragan, M.A., Hyatt, A.D., MacDonald, K.R., Hines, H.B., Lips, K.R., Marantelli, G. \& Parkes, H. 1998: Chytridiomycosis causes amphibian mortality associated with population declines in the rainforests of Australia and Central America. Proceedings of the National Academy of Sciences, USA 95: 9031-9036.

Berger, L., Speare, R., Hines, H., Marantelli, G., Hyatt, A.D., McDonald, K.R., Skerratt, L.F., Olsen, V., Clarke, J.M., Gillespie, G., Mahony, M., Sheppard, N., Williams, C. \& Tyler, M. 2004: Effect of season and temperature on mortality in amphibians due to chytridiomycosis. Australian Veterinary Journal 82: 31-36.

Boyle, D.G., Boyle, D.B., Olsen, V., Morgan, J.A.T. \& Hyatt, A.D. 2004: Rapid quantitative detection of chytridiomycosis (Batrachochytrium dendrobatidis) in amphibian samples using teal time Taqman PCR assay. Disease in Aquatic Organisms 60: 141-148.

Daszak, P., Berger, L., Cunningham, A.A., Hyatt, A.D., Green, D.E. \& Speare R. 1999: Emerging infectious diseases and amphibian population declines. Emerging Infectious Diseases 5: 735-48.

Daszak, P., Cunningham, A.A. \& Hyatt, A.D. 2003: Infectious disease and amphibian population declines. Diversity and Distributions 9: 141-150.

Fellers, G.M., Green, E. \& Longcore, J.E. 2001: Oral chytridiomycosis in the yellow-legged frog (Rana muscosa). Copeia 2001 (4): 945-953.
Gosner, K.L. 1960: A simplified table for staging anuran embryos and larvae with notes on identification. Herpetologica 16 : 183-190.

Gillespie, G. \& Marantelli, G. 2000: The role of the amphibian chytridiomycete fungus in population dynamics of the spotted tree frog (Litoria spenceri) a declining riverine species in south-eastern Australia. Getting the Jump! On Amphibian Disease: Conference and Workshop compendium. Cairns August, 2000, p.45.

Hardman, C. 2001: The potential impacts of the chytrid fungus on Tasmania's frog populations. Unpublished BSc (Hons) thesis, School of Zoology, University of Tasmania.

Johnson, M.L. \& Speare, R. 2003; Survival of Batrachochytrium dendrobatidis in water: quarantine and disease control implications. Emerging Infectious Diseases 9: 922-925.

Lawrence, W.F. 1996: Why are Queensland's frogs croaking? Nature Australia 25(4): 56-62.

Littlejohn, M.J. 2003: Frogs of Tasmania. Fauna of Tasmania Handbook No. 6 University of Tasmania, Hobart: 80 pp.

Martin, A.A. \& Littlejohn, M.J. 1982: Tasmanian Amphibians. Fauna of Tasmania Handbook No. 6, University of Tasmania, Hobart: 80 pp.

McDonald, K.R. \& Speare, R. 2000: Banana frogs: what's in the box? Fourth Australian Banana Industry Congress, Cairns, Australia (abstract).

Obendorf, D.L. 2005: Application of field ind diagnostic methods for chytridiomycosis in Tasmanian frogs. Central North Field Naturalists Inc. (Report to the Department of Environment and Heritage, Canberra) http://www. deh.gov.au/biodiversiry/invasive/publications/tasmanianfrogs/index.html

O'Dwyer, W.T., Buttemer, W.A. \& Priddel, D.M. 2000: Inadvertent translocation of amphibians in the shipment of agricultural produce into New South Wales: its extent and conservation implications. Pacific Conservation Biology 6: 40-45.

Powell, M.J. 1993: Looking at mycology with a Janus face: a glimpse of chytridiomycetes active in the environment. Mycologica 85: $1-19$

Rachowicz, L.J. 2002: Mouthpart pigmentation in Rana muscosa tadpoles: seasonal changes without chytridiomycosis. Hetertological Review 33: 263-265.

Speare, R., Berger, L., Skerratt, L.F., Alford, R., Mendez, D., Cashins, S., Kenyon, N., Hauselberger, K. \& Rowley, J. 2005: Hygiene protocol for handling amphibians in field studies. http://www.jcu.edu.au/school/phtm/PHTM/ frogs/field-hygiene.pdf

Stuart, S.N., Chanson, J.S., Cox, N.A., Young, B.E., Rodrigues, A.S., Fischman, D.L. \& Waller, R.W. 2004: Status and trends of amphibian declines and extinctions worldwide. Science 306: 1783-1786.

Weldon, C., Du Preez, L., Hyatt, A., Muller, R. \& Speare R. 2004: Origin of the amphibian chytrid fungus. Emerging Infectious Diseases 10: 2100-2105

(accepted 2 October) 